\title{
Factors Influencing the Adoption of Information Technology in a Construction Business
}

Kimberley Sargent, Paul Hyland and Sukanlaya Sawang, (Queensland University of Technology, Australia)

\begin{abstract}
Construction firms are increasingly utilizing information technologies to better manage geographically dispersed projects. Often these technologies involve changes to existing working practices and processes and are viewed as disruptive by members of the organization. Understanding the factors that can influence individuals' intention to utilize technology can assist managers to implement strategies to increase and improve the uptake of technologies and improve the innovation adoption process. Using a case study organization, factors identified in the Unified Theory of Acceptance and Use of Technology (UTAUT) are examined and the UTAUT is extended by including resistance to change and top management support. The findings indicate effort expectancy, internal facilitating conditions and top management support all influence individuals' intention to use information technology. The results also show that resistance to change or fear of change does not always play a role in innovation adoption. The findings reinforce the need to support new technologies from both a managerial and technical perspective.
\end{abstract}

Keywords: Technology adoption, Resistance, Organizational change, Top management support

\section{Introduction}

Information technologies can assist project and construction managers to standardize routine tasks so that available organizational resources are utilized both effectively and efficiently (Adam et al., 2007). Past research has shown organizational benefits from IT adoption for construction management (Bjork, 2003; Kaner et.al., 2008; Oyediran \& Odusami, 2005) The project management profession in recent years has grown exponentially and information technologies are used by many organizations to meet business requirements (Kendra and Taplin, 2004). Information technologies are commonly used to assist project managers with direct control over business functions, personnel and other resources (Hobday, 2000). As project managers oversee resource coordination and allocation it can be difficult to coordinate business functions across various projects. Information technologies are one of the key innovations that are frequently implemented to assist this process (Hobday, 2000). Peansupap and Walker (2005) maintain that information technologies are often implemented as they are believed to facilitate communication and improve integration (Bjork, 1999) as well as enhance productivity and service delivery.

Peansupap and Walker (2005) also maintain that the benefits of innovations such as information technologies can be limited if the adoption and use is poorly diffused, as effective diffusion requires user acceptance. Poor user acceptance can occur when transitioning from an existing system to a new system such as transitioning from a paper-based to a fully electronic environment; such a transition requires users who will readily adopt and utilize the information technology (Peansupap and Walker, 2005).When organizations implement a new technology, commonly they are not ready to adopt that technology and employees resist its introduction.

The technology adoption decision within organizations is usually authorized by a group of senior managers (Peansupap and Walker, 2005), therefore a key question of information 
technology adoption in construction firms should be how to ensure that users accept and utilize information technology in their work processes. However, studies indicate that the rate of unsuccessful information technology implementations is growing and further, the adoption rate is very slow (Acar et al., 2005; Mole et al., 2004; Shin, 2006). To address this poor success rate in adoption and contribute to Gambatese and Hallowell's (2011) call to identify the characteristics of innovation adopters, individual and managerial factors that impact on intention to utilize a specific information technology in a construction firm were studied.

\section{Information Technologies}

There is a positive relationship between IT adoption and organizational performance in the construction industry. For example, Construction Industry Institute (CII) and the National Institute of Standards and Technology (NIST) empirically examined the impact of IT adoption and found that cost and schedule performance improve with increased IT use (Thomas 1999; Thomas et al. 2001). Similar to these studies, Kang et.al (2008) employed Cll data from 139 projects from 74 companies examining the impact of IT adoption and project performance. Their findings also supported previous studies that level of IT adoption positively associated with improved performance. It is not sufficient to simply select the appropriate technology and implement it throughout an organization. According to Hussain and Wearne (2005), the construction and defence industries have adopted project management technologies to deal with the growth in scale, complexity and financial risks of capital projects, yet the number of defence projects that fail or blow out in terms of time and budget is well publicised. While Yang (2007) maintains that the use of technologies to enhance project performance has been widely supported, simply having innovative information technologies does not guarantee a project will be delivered on-time or within budget.

Yang (2007) maintains that studies have shown that the construction industry is reluctant to apply new technologies and employs lower levels of technology than other industries. One issue related to poor uptake that has emerged is organizational inertia, which Lawrence and Scanlan (2007) found means organizations tend to become accustomed to their own tools and technologies, and they find it difficult to give up and change established procedures and familiar information technology products. Therefore, changing existing ways of doing things or resistance to change (RTC) can pose problems. While Gambatese and Hallowell (2011) found that fear of change was a significant barrier to implementation of innovations such as information technologies unless this fear is translated into active or passive resistance it will not have a major impact on implementation or intention to use a technology. There is a need therefore to measure the RTC rather than fear of change. Critically on large projects it is essential to establish common integrated information technologies, as well as common methods and processes (Lawrence and Scanlan, 2007). Even when information technologies are available and are being used they are interpreted and utilized in different ways by different people.

Guss (1998) also found that project management professionals are inclined to be at different phases of acceptance and willingness to change in relation to adopting, planning and communicating information technologies. Often existing project management materials are too technical for the novice project manager and team (Longman and Mullins, 2004). The benefits of project management tools such as information technologies do not appear to justify the investment of time and energy and in some cases project managers perceive these technologies to be unproven or ineffective (Longman and Mullins, 2004; Guss, 1998). It is critical that project managers in the construction industry continually seek innovative information technologies to overcome limitations and inefficiencies in managing projects. However better information technologies alone will not ensure more effective management of projects. It has been argued that user acceptance is a critical success factor for technology implementation and can be tested and predicted by several factors (Hu et al., 1999).

Sargent, K et al. (2012) 'Factors influencing the adoption of information technology in a construction business', Australasian Journal of Construction Economics and Building, 12 (2) 72-86 


\section{Factors Influencing Information Technology Adoption and Use}

The Unified Theory of Acceptance and Use of Technology (UTAUT) model developed by Venkatesh et al. (2003) is a useful starting point to investigate technology adoption. The UTAUT can be used to identify factors that influence the intention to use information technology to be adopted by an organization (Venkatesh et al., 2003). The UTAUT model was based upon conceptual and empirical similarities across user acceptance models. The UTAUT has been used in the IT adoption literature, including IT adopting for construction management (Adriaanse, Voordijk \& Dewulf, 2010; Hjelt \& Björk, 2007; Samuelson, 2011). However, these studies did not include additional constructs such as top management support (TMS) (Dong et al., 2009) or resistance to change (Venkatesh et al., 2000), which have been identifies as influencing technology adoption. TMS plays a crucial role in determining technology implementation success and failure (Neufeld, Dong, \& Higgins, 2007). Similarly, resistance to change is also a vital factor for technology adoption because resistance is often the main reason a technology fails (Venkatesh et.al., 2001). This study, thus, adopts the UTAUT to examine IT adoption in construction management, similar to previous studies, but we also include two important constructs TMS and resistance to change which have also been identified as important to IT adoption.

According to the UTAUT model, seven constructs were found to be significant determinants of intention or usage in one or more of the individual user acceptance models examined (Venkatesh et al., 2003). Of the seven, Venkatesh et al. (2003) theorised that four would play a significant role as direct determinants of user acceptance and usage behaviour, namely performance expectancy, effort expectancy, social influence and facilitating conditions. In their study (Venkatesh et al., 2003), the UTAUT model was shown to be a good predictor of user acceptance and adoption of information technologies.

Performance expectancy is defined by Venkatesh et al. (2003, p.447) as 'the degree to which an individual believes that using a particular technology will help him or her to attain gains in job performance'. Venkatesh et al. (2003) propose that performance expectancy captures the constructs of perceived usefulness, extrinsic motivation, job fit, relative advantage and outcome expectations. Perceived usefulness has been strongly related to usage intentions in various studies (Davis, Bagozzi \& Warshaw, 1989) and Davis et al. (1992, p.1112) define it as 'a person's expectation that using the technology will result in improved job performance:

\section{Hypothesis 1: Performance expectancy will have a significant positive influence on individuals' intention to use an information technology.}

Effort expectancy is the 'degree of ease associated with the use of the system' (Venkatesh et al., 2003, p. 450). There are three existing constructs that capture the essence of effort expectancy, namely ease of use, complexity and perceived ease of use. Ease of use is defined by Moore and Benbasat (1991) and Davis et al. (1989) as the 'degree to which an individual believes that using a particular system would be free of physical and mental effort'. Complexity relates to the degree to which a technology is perceived as relatively difficult to understand and use (Thompson \& Higgins, 1991):

\section{Hypothesis 2: Effort expectancy will have a significant positive influence on individuals' intention to use an information technology.}

Social influence is 'the degree to which an individual perceives that important others believe he or she should use the new system' (Venkatesh et al., 2003, p.451). Three items contribute to the social influence construct: subjective norms, social factors and image. Subjective norms are a construct that has been widely researched in technology adoption

Sargent, K et al. (2012) 'Factors influencing the adoption of information technology in a construction business', Australasian Journal of Construction Economics and Building, 12 (2) 72-86 
literature. Ajzen (1991) and Mathieson (1991) define the construct as the perceived social pressure to perform or not to perform a behaviour:

Hypothesis 3: Social influence will have a significant positive influence on individual's intention to use an information technology.

Facilitating conditions is the final construct identified by Venkatesh et al. (2003, p.453) and is 'the degree to which an individual believes that organizational and technical infrastructure exists to support use of the system'. Three items are used to measure the facilitating conditions construct, namely perceived behavioural control, facilitating conditions and compatibility. The facilitating conditions construct was examined by Thompson and Higgins (1991) and was described as the objective factors present that make an act easy to do. Thompson and Higgins (1991) examined information technologies and found that training users and assisting them when they encounter difficulties is an example of a facilitating condition that can influence technology utilisation:

Hypothesis 4: Facilitating conditions will have a significant positive influence on individuals' intention to use an information technology.

\section{Influence of Top Management Support and Resistance to Change}

In spite of the empirical applicability of the UTAUT, additional efforts are needed to validate existing research results, in particular those involving different industry sectors, users or organizational contexts. Gallivan (2000) argued that generic innovation adoption models may not be applicable under the several circumstances:

- adoption within organizations where expected users are mandated to adopt;

- adoption is dependent on multiple adopters; and

- adoption requires extensive training to upgrade users' skills.

As generic adoption models rely on voluntary adoption decisions by individuals, they may be less suitable in explaining complex organizational adoption decisions (Gallivan, 2000). So in the context where a technology is mandated it is important to consider non-generic factors such as the influence of senior managers. Successful technology adoption by expected users in construction firms requires implementation support and encouragement from senior managers if individuals are to adopt and utilize the technology (Peansupap and Walker, 2005).

As senior managers can influence the implementation and use of new technologies, which according to Young and Jordan (2008) involves managers devoting time to the technology in proportion to its costs and potential, as well as reviewing plans, monitoring results and facilitating the management problems involved with integrating the technology with the management process of the business. Dong et al. (2009) also maintain that TMS encourages technology usage and better user performance, influences positive user perceptions and improves the overall technology adoption uptake. Similarly Gambatese and Hallowell (2011) found that effective upper management support was one of the strongest enablers on innovation implementation in construction firms. TMS is viewed as a clear commitment and allocation of sufficient resources to the innovation and if needed active involvement in managing change and innovation adoption (Gambatese and Hallowell 2011). According to Neufeld et al. (2007), TMS plays a crucial role in determining technology implementation success and failure. Furthermore, Ifinedo (2008) argues that a substantial body of knowledge has linked TMS to large scale technology implementation success. In terms of the UTAUT model, the facilitating conditions construct does not specifically measure TMS. According to Neufeld et al. (2007), the TMS construct has not been

Sargent, K et al. (2012) 'Factors influencing the adoption of information technology in a construction business', Australasian Journal of Construction Economics and Building, 12 (2) 72-86 
sufficiently integrated into existing user adoption theories, nor has literature defined specific top management behaviours that are associated with technology implementation success:

\section{Hypothesis 5: Top management support will have a significant positive influence on individuals' intention to use an information technology.}

Individual RTC is defined as an 'individual's dispositional inclination to resist change and predict reactions to specify change' (Oreg, 2003, p.680). It is a natural part of the organizational change process and individual resistance occurs because change involves going from the known to the unknown (Bovey and Hede, 2001). Individual RTC is an important factor for technology implementation because resistance is often one of the main reasons a technology fails (Venkatesh et al., 2000). When technologies are implemented, people differ from each other in their inclinations to resist or implement changes, therefore the theory surrounding RTC and the RTC scale can help explain why some people are more inclined than others to try to implement and use new technologies (Oreg et al., 2005). The RTC scale, developed by Oreg (2003, p.680), was designed to assess 'an individual's tendency to resist or avoid making changes'. Oreg (2003) states that using the RTC scale is far more economical as it uses a broad range of measures that tap into different aspects of RTC, rather than broader measures. Four personality-based aspects are assessed by the RTC scale: routine seeking, emotional reaction to change, short-term focus and cognitive rigidity (Oreg et al., 2009). Routine seekers are individuals who enjoy and seek out stable and lasting routines in their lives. Emotional reactors to change are how individuals respond to imposed changes. An individual who has short term focus focuses on short term hassles that are part of most changes; otherwise they focus on the potential long term benefits of change. Cognitive rigidity refers to an individual's tendency to maintain one's view. The combination of the four dimensions captures a variety of elements that predispose individuals to resist and avoid changes:

Hypothesis 6: Resistance to change will have a significant negative influence on individuals' intention to use an information technology.

Drawing together the UTUAT model, RTC and TMS an extended model emerges as can be seen in Figure 1. Figure 1 also includes age, gender, education and computer experience which are control variables, but may influence a users intention to adopt an information technology and are worth investigating in this context.

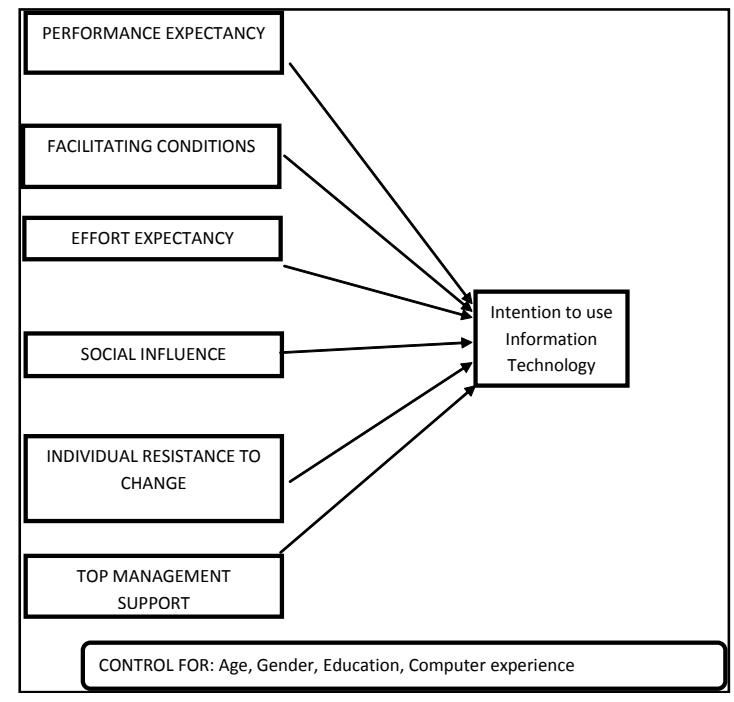

Figure1 Modified unified theory of acceptance and use of technology model

Sargent, K et al. (2012) 'Factors influencing the adoption of information technology in a construction business', Australasian Journal of Construction Economics and Building, 12 (2) 72-86 


\section{Method}

\section{Participants}

The case organization is a privately owned and operated Australian civil engineering and building construction company specializing in project management, infrastructure, engineering, building, mining services and precast. It is a medium-sized (650 employees) organization that has successfully delivered projects such as civil engineering construction, complex bridgeworks, large scale concrete works and retaining wall construction across geographically dispersed locations. The project management unit was introduced in early 2009 and it provides internal and external clients with excellence in project advisory services. The project management unit has since been continually seeking to improve training, project management qualifications and delivery. The business had recently identified issues in storing and accessing their working files, often from remote locations. The organization introduced an information management system which offers a comprehensive document control system and the software enables employees to save time and money by leveraging and reusing existing data, business processes and applications. Management believes the introduction of the document control system will enable end users to better manage files and file access.

Throughout the data collection process, the researchers received emails from respondents who were unable to complete the survey due to being offsite and not able to sustain an internet connection to complete the survey. The information obtained indicated that employees had experienced internet connection problems whilst working at rural locations. Further, these rural locations only had limited internet access at the site during peak hour. This situation restricted employees from retrieving information that they had stored on the document control system. Employees indicated that they were frustrated with the way technology restricted and hindered the efficient operation of the project.

Ruigrok and Gibbert (2010) argue that case study data can be collected using both qualitative and quantitative methods and argue that the use of questionnaires with validated measures increases the rigour of case study research. In this case study both qualitative and quantitative techniques were used to collect data, however, here results focus on quantitative analysis as two new measures are put forward and tested. The quantitative data was collected from 147 respondents who completed the survey (22.61\% response rate). The respondents were 104 males $(70 \%)$ and 43 females (30\%). Average respondents' age was 35 years $(S D=9)$ ranging from 19 to 60 years. Average computer technology usage experience was 15 years $(S D=7)$. The majority of respondents held undergraduate $(39 \%)$ and postgraduate $(27 \%)$ degrees. Respondents had an average organizational tenure of three years $(S D=3.25)$, ranging from one to 20 years.

\section{Measures}

Measures were adapted from well established and validated scales of UTAUT (Venkatesh et al., 2003), and the RTC scale, which was adapted from Oreg's (2003) study. This scale consists of 4 constructs; routine seeking, emotional reaction, short term focus and cognitive rigidity. TMS was measured using 5 items relating to management commitment to using the technology, management's commitment to support staff efforts and their commitment to encouraging the use of technology, as well as their general support for technology and there emphasis on the importance of the technology to the business. A five-point Likert scale was employed to measure the attitudes designed to allow respondents to signify how strongly they agree or disagree with established measures that range from very positive to very negative toward an attitudinal object.

\section{Data Analysis}

Data collected using multidimensional scales (e.g. UTUAT, TMS and resistance to change) were initially analysed using a principal components analysis with varimax rotation. The 
Exploratory Factor Analysis was conducted using SPSS/PASW (18.0) to determine how a range of change items loaded onto factors derived from a combined data set $(\mathrm{N}=147)$. For this analysis, a Principal Axis Factoring (PAF) extraction method was used with a varimax rotation. Ten series of the EFA were conducted and as a result, eight factors loaded cleanly and clearly. Two constructs (facilitating conditions and social influence) loaded onto one factor. It appeared that respondents perceived the social influence (1-item: senior management at our company has been helpful in the use of the document control system) and facilitating conditions (3-item: resources, knowledge and technical assistance) as their internal facilitator assisting them or encouraging them to adopt the document control system. Therefore, the two constructs were combined and renamed as 'internal facilitating conditions'. Hypothesis 3 and Hypothesis 4 were amended:

Hypothesis 3/4: Internal facilitating conditions will have a significant positive influence on individuals' intention to use the information technology.

Table 1 exhibits the correlations between the variables studied. Performance expectancy is significantly and positively associated with behavioural intention $(r=.36, p<.001)$; such that an increase in perceived performance expectancy is associated with an increase in behavioural intention to adopt the PM tool.

A significant positive relationship exists between effort expectancy and behavioural intention $(r=.47, p<.001)$ such that when perceived effort expectancy increases, perceived behavioural intention increases. A significant positive relationship exists between internal facilitating conditions and behavioural intention $(r=.48, p<.001)$ such that when perceived internal facilitating conditions increase, behavioural intention increases. A significant positive relationship exists between TMS and behavioural intention $(r=.40, p<.001)$ such that when perceived TMS increases, behavioural intentions increase. A significant negative relationship exists between emotional reaction and behavioural intention $(r=-.19, p<.05)$, such that when perceived emotional reaction increases, behavioural intention increases.

To examine the internal reliabilities for the measures, the Cronbach alpha was examined. Table 1 indicates that seven out of the nine internal reliabilities are above the threshold ( $\alpha$ $>0.70$ ), demonstrating that performance expectancy, effort expectancy, internal facilitating conditions, TMS, emotional reaction, short term focus and behavioural intention have demonstrated high consistency among items. Routine seeking and cognitive rigidity were amongst the few that displayed low internal reliabilities (below .70).

Modelling procedures together with multiple regression analyses were undertaken to determine the extent to which internal facilitating conditions, performance expectancy, effort expectancy, TMS and individual RTC predicted intention to use the document control system. Hierarchical regression analyses was utilized rather than structural equation modelling (SEM), as according to Buhi et al. (2007) having an adequate sample size is a major concern in SEM utilisation. Small samples are most likely to result in unreliable and untrustworthy parameter estimates and fit statistics yielding models that are nonreplicable. They suggested at least 200 cases are needed for adequate model specification.

On Block 1 of the series of multiple hierarchical regressions, all control variables (gender, education, computer experience and age) were entered as the independent variables (IVs). The behavioural intention dependent variable (DV) was also entered on Block 1. Having specified the first Block in the hierarchy, all UTAUT IV's (performance expectancy, effort expectancy and internal facilitating conditions) were entered on Block 2 of the regression. As noted in the literature review, theory indicates that the UTAUT constructs are significant predictors of the behavioural intention DV. On Block 3 of the regression, individual RTC and TMS were entered as IVs. Individual RTC and TMS were entered on the last Block to

Sargent, K et al. (2012) 'Factors influencing the adoption of information technology in a construction business', Australasian Journal of Construction Economics and Building, 12 (2) 72-86 
examine the significant effect of this additional regression equation. The results of the multiple hierarchical regressions follow.

Table 2 displays the results of the multiple hierarchical regressions conducted to examine the effect that the eight IVs had on the behavioural intention DV while controlling for gender, age, education and computer experience.

The entry of the covariates (computer experience, education, gender and age) in Step 1 did not further explain variance on behavioural intention $\left(\right.$ Adj. $\left.\mathrm{R}^{2}=-.02, F(4,117)=.53, n s\right)$. A positive insignificant relationship existed between gender and behavioural intention $(\beta=.13$, $n s)$, and computer experience and behavioural intention $(\beta=.09, n s)$. A negative insignificant relationship exists between age and behavioural intention $(\beta=-.01, n s)$, and education and behavioural intention $(\beta=-.00, n s)$.

On Block 2 of the regression, the UTAUT constructs as IVs (effort expectancy, internal facilitating conditions and performance expectancy) were entered to examine the direct effect they have on behavioural intention. The entry of these three IVs explained an additional $16.9 \%$ variance to the model $\left(\Delta \mathrm{R}^{2}=.17, F(3,114)=7.93, p<.001\right)$. A positive significant relationship exists between effort expectancy and behavioural intention $(\beta=.19, p$ $<.05)$ such as when perceived effort expectancy increases, perceived behavioural intention increases. Furthermore, a significant positive relationship exists between internal facilitating conditions and behavioural intentions $(\beta=.37, p<.001)$ whereby when perceived internal facilitating conditions increase, perceived behavioural intentions increase. Finally, a positive non-significant relationship was observed between performance expectancy and behavioural intention $(\beta=.16, n s)$.

On Block 3 of the regression, the TMS and RTC 1 to RTC 4 as IVs (TMS, RTC 1: Emotional reaction, RTC 2: short term focus, RTC 3: routine seeking, and RTC 4: cognitive rigidity) were entered to examine the additional effect they have on behavioural intention. The entry of these IVs explained an additional $7 \%$ variance to the model $\left(\Delta R^{2}=.07, F(5,109)=2.03\right.$, $n s)$. The TMS construct significantly and positively predicted behavioural intention $(\beta=.18$, $p<.05)$ such that when perceived TMS increases, perceived behavioural intention increases. The emotional reaction component of the RTC scale negatively but nonsignificantly predicted behavioural intention $(\beta=-.08, n s)$, as well as the short term focus construct negatively but non-significantly predicted behavioural intention $(\beta=-.12, n s)$. The routine seeking construct positively but non-significantly predicted the behavioural intention DV $(\beta=.15, n s)$. The cognitive rigidity construct also negatively but non-significantly predicted behavioural intention $(\beta=-.08, n s)$.

In conclusion, after undertaking the multiple hierarchical regressions to test the proposed hypotheses, the following hypotheses were supported:

H2: Effort expectancy positively influenced individuals' intention to use the
information technology.
H3/4: Intermal facilitating conditions positively influence individuals' intention to use
the information technology.

H5: Top management support positively influences individuals' intention to use the information technology. 


\begin{tabular}{|c|c|c|c|c|c|c|c|c|c|c|c|c|}
\hline & Mean (SD) & 1 & 2 & 3 & 4 & 5 & 6 & 7 & 8 & 9 & 10 & 11 \\
\hline 1. Performance expectancy & $1.61(.77)$ & $(.89)$ & & & & & & & & & & \\
\hline 2. Effort expectancy & $2.93(.94)$ & $.55^{\star \star \star}$ & $(.90)$ & & & & & & & & & \\
\hline $\begin{array}{l}\text { 3. Internal facilitating } \\
\text { conditions }\end{array}$ & $3.23(.87)$ & $.44^{* \star \star}$ & $.55^{\star \star \star}$ & $(.80)$ & & & & & & & & \\
\hline 4. Top management support & $4.09(.79)$ & $.34^{\star \star \star}$ & $.33^{\star * \star}$ & $.63^{\star \star \star}$ & $(.88)$ & & & & & & & \\
\hline $\begin{array}{l}\text { 5. Resistance to change - } \\
\text { Routine seeking }\end{array}$ & $1.34(.52)$ & $-.14^{*}$ & $-.24^{* \star}$ & -.11 & -.06 & $(.57)$ & & & & & & \\
\hline $\begin{array}{l}\text { 6. Resistance to change - } \\
\text { Emotional reaction }\end{array}$ & $1.73(.58)$ & -.04 & $-.21^{* \star}$ & -.09 & -.00 & $.33^{\star \star \star}$ & $(.76)$ & & & & & \\
\hline $\begin{array}{l}\text { 7. Resistance to change - } \\
\text { Short term focus }\end{array}$ & $1.35(.52)$ & -.06 & -.11 & -.11 & -.06 & $.21^{\star \star}$ & $.37^{\star \star \star}$ & $(.74)$ & & & & \\
\hline $\begin{array}{l}\text { 8. Resistance to change - } \\
\text { Cognitive rigidity }\end{array}$ & $2.82(.82)$ & .00 & .08 & .09 & -.02 & .05 & -.03 & .09 & $(.61)$ & & & \\
\hline $\begin{array}{l}\text { 9. Behavioural intention to } \\
\text { adopt the document control } \\
\text { system }\end{array}$ & $3.97(.92)$ & $.36^{* \star *}$ & $.47^{* \star *}$ & $.48^{\star \star \star}$ & $.40^{* * *}$ & -.14 & $-.19^{\star *}$ & -.06 & .09 & $(.70)$ & & \\
\hline 10. Computer experience & $14.79(6.58)$ & .11 & $.17^{\star \star}$ & -.10 & .00 & $-.20^{\star \star \star}$ & $-.22^{* * *}$ & -.09 & $.19^{* \star}$ & $.14^{\star}$ & & \\
\hline 11. Education & $3.52(1.15)$ & .11 & .06 & .07 & .07 & -.01 & -.04 & $-.23^{* \star *}$ & -.12 & .02 & $.20^{* *}$ & \\
\hline 12. Age & $35.32(8.91)$ & .05 & -.09 & $-.17^{* *}$ & -.11 & -.12 & -.12 & -.04 & $.15^{\star \star}$ & .02 & $.53^{* \star *}$ & .07 \\
\hline
\end{tabular}

Table 1 Descriptive data for focal variables for the study

Note. Cronbach alpha reliability coefficients appear in the diagonals. ${ }^{*} p<.05 ;{ }^{* *} p<.01 ;{ }^{* *} p<.001$

Sargent, K et al. (2012) 'Factors influencing the adoption of information technology in a construction business', Australasian Journal of Construction Economics and Building, 12 (2) 7286 


\begin{tabular}{|c|c|}
\hline Predictors & $\begin{array}{l}\text { Intention to adopt the document control } \\
\text { system } \\
\beta\end{array}$ \\
\hline \multicolumn{2}{|l|}{ Regression 1} \\
\hline \multicolumn{2}{|l|}{ Step 1 - Covariates } \\
\hline Age & -.01 \\
\hline Gender & .13 \\
\hline Computer experience & .09 \\
\hline Education & -.00 \\
\hline Adj. $R^{2}$ & -.02 \\
\hline \multicolumn{2}{|l|}{ Step 2 - Main effect - UTAUT } \\
\hline Effort expectancy & $.19^{*}$ \\
\hline Internal facilitating conditions & $.37^{* * *}$ \\
\hline Performance expectancy & .16 \\
\hline $\mathrm{R}^{2} \mathrm{Ch}$ & $.17^{* \star *}$ \\
\hline \multicolumn{2}{|l|}{$\begin{array}{l}\text { Step 3-Main effect - Top management support } \\
\text { and Resistance to change }\end{array}$} \\
\hline Top management support & $.18^{*}$ \\
\hline Resistance to change 1: Emotional reaction & -.08 \\
\hline Resistance to change 2 : Short term focus & -.12 \\
\hline Resistance to change 3: Routine seeking & .15 \\
\hline Resistance to change 4 : Cognitive rigidity & -.08 \\
\hline $\mathrm{R}^{2} \mathrm{Ch}$ & .07 \\
\hline
\end{tabular}

Table 2 Hierarchical multiple regression analysis showing main effects of UTAUT, resistance to change and TMS on intention to adopt the document control system

${ }^{*} \mathrm{p}<.05 ;{ }^{* *} \mathrm{p}<.01 ;{ }^{* * *} \mathrm{p}<.001$

\section{Discussion}

This study examined individual and managerial factors which impact on intention to utilize a specific information technology in a project-based organization, extending the UTAUT model. Effort expectancy and internal facilitating conditions positively predicted an intention to use the document control system. The literature supports that users' perceptions of ease of use and usefulness are amongst some of the most important indicators for behavioural intention to adopt and implement a new technology (Lu et al., 2005). What is interesting about this finding pertains to the demographics of the respondents. It is very likely that the high levels of computer experience were contributory to this hypothesis being supported. The demographics of this sample had an average of 15 years computer experience and most respondents $(39 \%)$ undergraduate $(27 \%)$ postgraduate had obtained an undergraduate degree. It can be assumed that the respondents were a highly skilled and educated cohort therefore adapting to the new technology and learning how to use it did not pose a significant problem.

Performance expectancy did not influence an intention to use the document control system. This can be explained by the fact that information technology is intended to minimize effort and time required for planning and monitoring projects (Ali, Anbari, \& Money, 2008);

Sargent, K et al. (2012) 'Factors influencing the adoption of information technology in a construction business', Australasian Journal of Construction Economics and Building, 12 (2) 72-86 
however, as the case organization is a project based organization (PBO) and project managers frequently find themselves away from the office, it is understandable that employees did not agree that the document control system enabled them to accomplished tasks more efficiently as access to the Internet in many remote locations was very limited.

In summary, in this case study the UTAUT model was partially supported (that is the effort expectancy and internal facilitating conditions constructs). It is noted here that this is the first time that the document control system has been tested as the technology to be adopted and it is not surprising that the majority of the UTAUT constructs fit well and predict intention to adopt; however, the UTAUT model was extended and this provides interesting insights and contributions.

\section{Top Management Support and Resistance to Change}

TMS influenced individuals' intention to adopt the document control system. This finding is supported by Dong et al. (2009), who argue that TMS encourages technology usage and better user performance, influences positive user perceptions and improves the overall technology adoption uptake. Similarly Gambatese and Hallowell (2011) found that effective upper management support was one of the strongest enablers of innovation implementation in construction firms. As the internal facilitating conditions also predicted a positive intention to adopt the document control system, it is logical that TMS is one of the factors that employees value when adopting a new technology.

TMS appears in two forms in the case study organization. Firstly, the document control system was implemented gradually to allow employees to transition from the old project management technology to the new technology. Eventually, the old system was to be discarded and employees had few options but to use the new system. This was a clear example of how management directly ensured technology uptake. Secondly, indirectly the institutional structures were manipulated as employees' current systems and the way of doing things were changed so that employees had little choice but to accept the change. Consistent with the literature presented by Murphy and Ledwith (2007), this case organization had clear goals and objectives for the technology implementation as well as perceived TMS. As the technology implementation was evolutionary in nature and these supporting factors were in place, it was more likely that the employees would intend to use the document control system if management were supportive (Murphy \& Ledwith, 2007).

While it has been suggested that with any organizational change, people are likely to develop some resistance to that change, in this case, a significant result was not found between RTC and intention to use the document control system. The overall RTC score was relatively low (1.94 out of 5). This is most likely due to the nature and structure of the organization, as it is project-based and continually evolving, therefore stable routines are far from apparent. The development of change resistance could be at an early stage and it may not be recognizable. Furthermore, the average length of service for employees at this case organization is three years with the most common length of service being two years. It could be assumed that because employees have not been employed for a long duration, they have not developed inertia to change. Contributory to this, $54 \%$ of the respondents are project-based indicating that their roles are continually changing due to projects in different locations. The literature reveals that RTC in PBOs refers directly to the lack of acceptance of change by the people affected and this causes projects to fail. It is evident that in the case organization, employees are well educated, experience continual change and operate in a dynamic environment. This may explain why there is not a significant relationship between RTC and intention to utilize the document control system.

Future research that should be considered includes firstly the testing of the UTAUT with other project management technologies. Secondly, because TMS was seen as a significant predictor of behavioural intention, this construct should be tested in other construction firms

Sargent, K et al. (2012) 'Factors influencing the adoption of information technology in a construction business', Australasian Journal of Construction Economics and Building, 12 (2) 72-86 
to verify its importance to be included in the UTAUT model. How crucial TMS is for technology adoption and implementation is already understood, but it would be interesting to test this construct alongside the UTAUT model in a different organizational context or perhaps other PBOs. Thirdly, the RTC should not be disregarded as an unimportant predictor of behavioural intention to adopt a technology. Due to the project-based context of the case organization, the organization is continually changing and is therefore used to change turbulence. The RTC should be tested along the UTAUT and TMS to further confirm or to disregard as a predictor of behavioural intention.

The research was limited in a number of important respects. The possibility of common methods bias always exists with self-report survey data of this kind. Notwithstanding this, future research should utilize varied data collection methods to overcome this potential source of bias. The research was undertaken as a baseline survey in a single PBO in which information technology was being adopted; further research needs to be conducted in a number of case study construction organizations. Also, further research needs to examine other factors identified by Gambatese and Hallowell (2011) such as organizational culture, the presence of an innovation champion and communication.

\section{Conclusions}

The theoretical implications that have developed from this study include the importance of TMS in a project-based environment and the RTC scale being tested in difference contexts. The two components of the UTAUT model that are still relevant to technology adoption in construction firms are effort expectancy and internal facilitating conditions. Although performance expectancy was not seen as a predictor of intention to use the project management technology, it is still seen as useful to test in construction organizations.

From a management perspective, RTC does not appear to be a major cause for concern. Management needs to support any technology adoption initiatives, for example encouraging employees to use the technology and demonstrating its benefits. The practical implications resulting from the RTC is that although it does not directly affect intention to adopt a new technology, it is a construct that definitely could prevent the general adoption of a technology. In particular, this could be the case for those employees who have longer service lengths and are set in their own ways. The emotional reaction construct did, however, influence the behavioural intention to use the information technology. Therefore, practical implications from this finding imply that management must be aware that if they change the processes that employees use regularly, their employees will feel stressed.

\section{References}

Acar, E., Kocak, I., Sey, Y. and Arditi, D. (2005) 'Use of information and communication technologies by small and medium-sized enterprises (SMEs) in building construction', Construction Management and Economics, 23, 713-722

Adam, F., Carton, F. and Sammon, D. (2007) 'Project management: a case study of a successful ERP implementation', International Journal of Managing Projects in Businesses, 1, 106-124

Adriaanse, A., Voordijk, H. and Dewulf, G. (2010) 'The use of interorganisational ICT in United States construction projects', Automation in Construction, 19 (1), 73-83

Ajzen, I. (1991) 'The theory of planned behavior', Organizational Behavior and Human Decision Processes, 50 (2), 179-211

Ali, A.S.B, Anbari, F.T and Money, W.H. (2008) 'Impacts of organisational and project factors on acceptance and usage of project management software and perceived project success', Project Management Journal, 39 (2), 5-33

Buhi, E. R, Goodson, P. and Neilands, T. B. (2007) 'Structural equation modelling: a primer for health behavior researchers', American Journal of Health Behavior, 31 (1), $74-85$

Sargent, K et al. (2012) 'Factors influencing the adoption of information technology in a construction business', Australasian Journal of Construction Economics and Building, 12 (2) 72-86 
Bovey, W. H. and Hede, A. (2001) 'Resistance to organisational change: the role of defence mechanisms', Journal of Managerial Psychology, 16 (7/8), 534-548

Bjork, B.-C. (1999) Information technology in construction: domain definition and research issues', International Journal of Computer Integrated Design and Construction, SETO, 1 (1), 3-16

Bjork, B.-C. (2003) 'Electronic document management in construction: research issues and results'. ITcon, 8, 105-117

Davis, F.D. (1989) 'Perceived usefulness, perceived ease of use, and user acceptance of information technology', MIS Quarterly, 13 (3), 319-340

Davis, F.D., Bagozzi, R.P. and Warshaw, P. R. (1989) 'User acceptance of computer technology: a comparison of two theoretical models', Management Science, 35 (8), 982 1003

Davis, F. D., Bagozzi, R.P. and Warshaw, P. R. (1992) 'Extrinsic and intrinsic motivation to use computers in the workplace', Journal of Applied Social Psychology, 22 (14), 1111-1132

Dong, L., Neufeld, D. and Higgins, C. (2009) 'Top management support of enterprise systems implementations', Journal of Information Technology, 24 (1), 55-80

Gallivan, M. J. (2000) 'Examining workgroup influence on technology usage: a community of practice perspective', Proceedings 2000 ACM SIGCPR, The conference on Computer personnel research, ACM Press Chicago, IL, 54-66

Gambatese, J. A. and Hallowell, M. (2011) 'Enabling and measuring innovation in the construction industry', Construction Management and Economics, 29 (6), 553-567

Guss, C. L. (1998) 'Virtual project management: tools and the trade', Project Management Journal, 29 (1), 22-31

Hjelt, M. and Bjork, B-C. (2007) 'End user attitudes towards EDM use in construction project work: a case study', American Society for Civil Engineering Journal of Computing in Civil Engineering, 21 (4), 289-300

Hobday, M. (2000) The project-based organisation: an ideal form for managing complex products and systems?', Research Policy, 29 (7-8), 871-893

Hu, P. J. Chau, P. Y. K, Liu Sheng, O.R and Kar Yan, T. (1999) 'Examining the technology acceptance model using physician acceptance of telemedicine technology', Journal of Management Information Systems, 16 (2), 91-112

Hussain, R. and Wearne, S. (2005) 'Problems and needs of project management in the process and other industries', Chemical Engineering Research and Design, 83 (4), 372-378

Ifinedo, P. (2008) 'Impacts of business vision, top management support, and external expertise on ERP success', Business Process Management Journal, 14 (4), 551-568

Kang, Y., O'Brien, W. J, Thomas, S. and Chapman, R. E. (2008) 'Impact of information technologies on performance: cross study comparison', Journal of Construction Engineering and Management, 134 (11), 852-863

Kaner, I., Sacks, R., Kassian, W. and Quitt, T. (2008) 'Case studies of BIM adoption for precast concrete design by mid-sized structural engineering firms', ITcon, 13 (Special Issue), 303-323

Kendra, K. A. and Taplin, L. J. (2004) 'Change agent competencies for information technology project managers', Consulting Psychology Journal: Practice and Research, 56 (1), 20-34

Lawrence, P. and Scanlan, J. (2007) 'Planning in the dark: why major engineering projects fail to achieve key goals', Technology Analysis \& Strategic Management, 19 (4), 509-525 
Longman, A. and Mullins, J. (2004) 'Project management: key tool for implementing strategy', Journal of Business Strategy, 25 (5), $54-60$

$\mathrm{Lu}, \mathrm{J}, \mathrm{Yu}, \mathrm{C}-\mathrm{S}$ and Liu, C. (2005) 'Facilitating conditions, wireless trust and adoption intention', The Journal of Computer Information Systems, 46 (1), 17-24

Mathieson, K. (1991) 'Predicting user intentions: comparing the technology acceptance model with the theory of planned behavior', Information Systems Research, 2 (3), 173-191

Mole, K. F., Ghobadian, A., O'Regan, N and Liu, J. (2004) 'The use and deployment of soft process technologies within UK manufacturing SMEs: an empirical assessment using logit models', Journal of Small Business Management, 42 (3), 303-324

Moore, G. C. and Benbasat, I. (1991) 'Development of an instrument to measure the perceptions of adopting an information technology innovation', Information Systems Research, 2 (3), 192-222

Murphy, A. and Ledwith, A. (2007) 'Project management tools and techniques in hightechnology SMEs', Management Research News, 30 (2), 153-166

Neufeld, D., Dong, L. and Higgins, C. (2007) 'Charismatic leadership and user acceptance of information technology', European Journal of Information Systems, 16 (4), 494-510

Oreg, S. (2003) 'Resistance to change: developing an individual differences measure', Journal of Applied Psychology, 88 (4), 680-693

Oreg, S., Goldenberg, J. and Frankel, R. (2005) 'Dispositional resistance to the adoption of innovations', Proceedings of the Annual Meeting of the European Association of Work and Organizational Psychology, May 2005, Istanbul, Turkey

Oreg, S., Nevo, O., Metzer, H., Leder, N. and Castro, D. (2009) 'Dispositional resistance to change and occupational interests and choices', Journal of Career Assessment, 17 (3), 312323

Oyediran, O. S. and Odusami, K. T. (2005) 'A study of computer usage by Nigerian quantity surveyors', ITcon, 10, 291-303

Peansupap, V. and Walker, D. H. T. (2005) 'Factors affecting ICT diffusion: a case study of three large Australian construction contractors', Engineering Construction and Architectural Management, 12 (1), 21-37

Ruigrok, W. and Gibbert, M. (2010) 'The "what" and "how" of case study rigor: three strategies based on published work', Organizational Research Methods, 13 (4), 710 - 737

Samuelson, O. (2011) 'Adoption processes for EDM, EDI and BIM technologies in the construction industry', Proceedings CIB W78-W102 2011, International Conference, 26-28 October, Sophia Antipolis, France

Shin, I. (2006) 'Adoption of enterprise application software and firm performance', Small Business Economics, 26, 241-256

Thomas, S. (1999) 'Impacts of design/information technology on project outcome'. Proceedings NIST GCR 99-786, 46 p, The Conference of the National Institute of Standards and Technology, Washington, D.C.

Thomas, S., Macken, C. and Lee, S. (2001) 'Impacts of design/information technology on building and industrial projects', Proceedings NIST GCR 01-828, The Conference of the National Institute of Standards and Technology, Washington, D.C.

Thompson, R. L. and Higgins, C.A. (1991) 'Personal computing: toward a conceptual model of utilization', MIS Quarterly, 15 (1), 125-143

Venkatesh, V., Morris, M. G. and Ackerman, P. L. (2000) 'A longitudinal field investigation of gender differences in individual technology adoption decision-making processes', Organizational Behavior and Human Decision Processes, 83 (1), 33-60 
Venkatesh, V., Morris, M. G., Davis, G. B. and Davis, F. D. (2003) 'User acceptance of information technology: toward a unified view', MIS Quarterly, 27 (3), 425-478

Yang, L-R. (2007) 'Exploring the links between technology usage and project outcomes', Construction Management and Economics, 25 (10), 1041-51

Young, R. and Jordan, E. (2008) 'Top management support: mantra or necessity?', International Journal of Project Management, 26 (7), 713-725 